\title{
Türkçe Söz Diziminde Taşıma ve Taşımanın Dönüşüme Etkisi
}

\section{Movement in Turkish Syntax and the Effect of Movement on Transformation}

\author{
Seçil HİRIK ${ }^{1}$
}

'Sorumlu yazar/Corresponding author: Seçil Hirik (Dr. Öğr. Üyesi), Nevşehir Hacı Bektaș Veli Üniversitesi, Eğitim Fakültesi, Türkçe ve Sosyal Bilimler Eğitimi Bölümü, Nevşehir, Türkiye

E-posta: secilhirik@gmail.com

ORCID: 0000-0002-2698-9350

Başvuru/Submitted: 13.06 .2019 Revizyon Talebi/Revision Requested: 17.07.2019

Son Revizyon/Last Revision Received: 18.09.2019

Kabul/Accepted: 26.09.2019

Online Yayın/Published Online: 26.11.2019

Atıf/Citation: Hirik, Secil. “Türkçe Söz Diziminde Taşıma ve Taşımanın Dönüşüme Etkisi." Türkiyat Mecmuasi-Journal of Turkology 29, 2 (2019): 403-418

https://doi.org/10.26650/iuturkiyat.651057 öz

Dil, kendi doğasına ve kurallarına sahip, insan üretimi olan bir olgudur. Dil belirli ilkeler çerçevesinde oluşum ve gelişimini devam ettirirken bir yandan da toplumdan topluma değişebilen özellikleri taşımaktadır. Salt dil olgusuyla ilgilenen dilbilimciler, bu üretim aracı için çeşitli kuramlar ortaya atmıştır. Bu yaklaşımlardan biri olan Evrensel Dil Bilgisi ya da Üretici Dönüşümsel Dil Bilgisi, Chomsky tarafından 1950'lerden itibaren gelişme kaydederek dilin ve dillerin yapısını anlama üzerine kurulmuş öncül kuramdır. Kuramın özünde yatan görüşler arasında tüm dillerin ortak ilkeler (principles) barındırdığı ancak her dilin de bir diğerinden ayrılan değiştirgenler (parameters) içerdiği yer almaktadır. Bahsi geçen ilkeler arasında söz dizimi sınırları içinde sayılacak olan dönüşüm (transformation) kavramı bulunmaktadır. Tüm dillerde derin yapısı aynı kalmak koşuluyla farklı dönüşüm işlemlerinden geçen yüzey yapılar görülmektedir. Kuramda söz edilen değiştirgenlerden biri dönüşümlerin dilden dile farklılık gösterebileceğidir. Dönüşümler ise ekleme, yeniden yazma, eksiltme (silme) ve taşıma gibi alt işlemleri içermektedir.

Bu çalışmada, kuramda yer alan ve Chomsky'nin ad öbeği taşıma (AÖ-taşıma), ne taşıma (ne-taşıma) ve baş unsur taşıma (baş-taşıma) olmak üzere üç türüne işaret ettiği taşıma türleri Türkçe örnekler üzerinden ele alınmıştır. Ancak bununla birlikte kuramda yer almayan ve Türkçede karşılaşılan bir ad öbeği taşıma örneği olan ettirgenleştirme, eylemsi taşıma ve tümce taşıma gibi taşıma işlemlerinin de uygulandığı dönüşümlere yer verilmiştir.

Anahtar kelimeler: Evrensel dil bilgisi, Üretici dönüşümsel dil bilgisi, İlkeler ve değiştirgenler kuramı, dönüşüm, taşıma

\section{ABSTRACT}

Language is a phenomenon of human production with its own nature and rules. While language maintains its formation and development within the framework of certain principles, it also carries characteristics that can change from one society to another. Linguists who are interested in pure language have put forward various theories for this production tool. One of these approaches, Universal Grammar or Generative-Transformational Grammar, is an early theory based on Chomsky's approach to understanding languages and their structure which he developed from the 1950s onwards. The core ideas of this theory are that all languages 
contain common principles, but that each language contains parameters that differ from one another. These principles include the concept of transformation which will be considered within the boundaries of syntax. In all languages, surface structures that have undergone different transformation processes can be seen provided that the deep structure remains the same. The transformations mentioned in the theory may differ from language to language. These include sub-processes such as addition, rewriting, reduction (deleting), and movement.

In this study, the three types of movement mentioned in the theory and referred to by Chomsky as noun phrase-movement, wh-movement and head-movement are discussed through Turkish examples. However, this study also includes examples of movement which are not part of the theory yet are encountered in Turkish, such as causativation, verbal-movement and sentence-movement.

Keywords: Universal grammar, Generative-transformational grammar, Principles and parameters theory, transformation, movement

\section{EXTENDED ABSTRACT}

There are a number of theories dealing with phonemes, free and bounded morphemes, and syntactic elements. In linguistic studies which examine language as a mere fact, the deep structure-surface structure pair, first introduced by Bloomfield, has been the guide to the functions of all language units by distinguishing what was said and not. Many linguistic theories on syntax have been put forward. One of these, Universal Grammar, or GenerativeTransformational Grammar, is one of the important approaches in identifying common values of language. The theory, which was proposed by Chomsky in the 1950s and which included different stages of development in later periods, brought important concepts with it. Competenceperformance (act), deep-surface structure, phrasal structure, and transformation-movement are among the remarkable and prominent concepts of the theory.

The main aim of this study is to consider the rules of movement which is one of the types of transformation mentioned in the theory. The other aim is to give examples from Turkish and to explain these in addition to Chomsky's three-types of movement in transformation, and to try to explain the existence of different types in Turkish.

This study uses a qualitative research method. The sentences given as examples are chosen from phrases that are possible in verbal language.

In Chomsky's general theory, namely the Theory of Principles and Parameters and the process of transformation, movement is a method that varies from language to language and can be realized in accordance with the possibilities offered by the syntax. In all languages, surface structures which have undergone different transformation and movement processes are observed.

Transportation and movement is a process applied to the deep structure by placing the deep structure in the surface structure. According to the theory, transportation and movement are applied to a constructor in the syntax and move the constructor to an empty location in the next syntax. The principle of movement is that the item being moved can only be moved to the position where an item from its category can be found (2006: 5). 
This study mentions the three types of movement that Chomsky demonstrates in his examples, especially in European languages: these are noun phrase-movement, head-movement, and whmovement. The most typical example of the noun phrase-movement is seen in passivation. The element that is in a given position in an active sentence fills the empty category in the new sentence when it is rewritten in a passive structured sentence. However, the element in the previous sentence, but not found in the second sentence leaves a trace in its place (Ex. a. "Ayşe bulaşıkları yıkadı." b. "Bulaşıklar yıkandı."). This trace is in the deep structure. In addition to this typical noun phrase-movement, this study gives examples of the causativation process which is shown to involve not only movement, but also the operation of addition (Ex. a. "Ayşe temizlikçilere evi temizlemeleri için emir verdi.”, b. "Ayşe evi (temizlikçilere) temizletti."). Also, it is seen that the sentences with verbals and ne... ne (de) conjunctions are also rewritten with noun phrase transportation as an example of phrase structure movement.

Different types of movement from noun phrase to the head-movement are not very common. In European languages (for example English), the subject and the auxiliary verb can be replaced (eg a. You are a student. , b. "Are you a student?"| You $\leftarrow \rightarrow$ Are). The head element in Turkish is moved when the verb in the predicate is in the position of time phrase by taking mood and time suffixes.

The last movement type discussed in the theory is wh-movement. This type of transport is not typical for Turkish, as is the case for head-movement.

Carrying question words is not typical in Turkish. The reason for this is the freedom of movement which can be applied in regular sentences. In Turkish syntax and in languages where there are no strict rules, question words can be found in all parts of the sentence in line with the logical structure they have established between them. Therefore, this transportation process is not a physical structure in Turkish, but a logical structure. 


\section{Giriş}

Evrensel dil bilgisinde dil yetisinin doğuştan geldiği, her dilin insanın bir ürünü olduğu ve her dilin kendi kurallarının bulunduğu mantığı yatmaktadır. Tüm dillerin ortak özellikleri olabildiği gibi bir dili diğerinden ayıran çeşitli değişkenler görülmektedir. Örneğin tüm dillerde var olan yüklemin ve yüklemdeki hareketin gerçekleşmesini sağlayan bir eyleyen varlığının ortak olduğu bilgisi gibi sözcük türlerinin varlığı da ortak kabul edilen özellikler arasındadır. Bununla birlikte yüklemin yeri, eyleyenin/öznenin açık veya gizli olarak tümcede yazılması, eyleyenin türleri, sözcük türlerinin sayısı ve alt kategorileri, sözcük yapım yolları, eklerin varlığı gibi bilgiler ise değişkenler arasında sayılabilir.

Türkçe sondan eklemeli ve yüklemi sonda bulunan kurallı diller arasındadır. Türkçeyi, Türkçe yapan ve diğer dillerden ayıran ses olayları, sözcük türetme/çekime sokma yolları, sözcük öbeklerinde asıl unsurun konumu ve durumu, tümceyi oluşturan bileşenler ve onların dizilimleri gibi pek çok özellik daha sayılabilir. Bu çalışma, Türkçenin söz dizimi alanında tümcenin dönüşüm (transformation) yolları ve bu yollardan biri olan taşıma (movement) işlemi ile ilgilidir. Söz konusu işlemler, Chomsky’nin Evrensel Dil Bilgisi ya da diğer adıyla Üretici Dönüşümsel Dil Bilgisi Kuramı temeli üzerinden ve Türkçe örneklerle aktarılacaktır. Kuramın ve işlemin mantığını anlamak için öncelikle kuram ve onun alt alanlarından bahsetmek gerekmektedir.

Kuram, ortaya çıktığı 1950'li yıllardan Chomsky'nin son dönemine kadar farklı gelişim evrelerinden geçmiştir. Hem kendini geliştiren bir yandan da değiştiren kuram 1957'den 1990'l1 yıllara kadar alt kuramlar geliştirerek kendini güncellemiştir. Kerimoğlu'nun çalışmasında da belirtildiği gibi Chomsky’nin genel kuramını Üretici Dönüşümsel Dilbilgisi, Standart Kuram, Genişletilmiş Standart Kuram, Yönetme ve Bağlam Kuramı ve Yetinmeci Program olmak üzere beş alt kuramda ele almak mümkündür. ${ }^{1}$ Üretici Dönüşümsel Dil Bilgisi Kuramı'nın temel kavramları arasında yer alan dönüşüm (transformation), söz diziminin tanıdığı imkân kadar tümcenin değişimini ele almaktadır. Chomsky’nin çekirdek tümce (kernel sentences) adını verdiği ve dil bilgisi çalışmalarında² kurallı tümce olarak geçen düz, olumlu ve soru formunda olmayan tümce tipi için kullandığı bu kavram, söz diziminin özünü teşkil etmektedir. Verilen bir tümcenin üretiminde zorunlu dönüşümler uygulandığında sonuç tümce (resulting sentence), çekirdek cümle (kernel sentence) olarak adlandırılmaktadır. Bir dönüşüm aygıtını içeren basit bir türün tümceleri olması bakımından çekirdek tümce kavramı, Chomsky için sezgisel öneme sahiptir. ${ }^{3}$ Buna göre örneğin Ali eve geldi. gibi bir tümce, çekirdek tümce olarak ele alındığında bundan üretilmiş ve ekleme, çıkarma ve yer değiştirmelerle değişimine uğramış Ali eve gelmedi., Ali eve geldi mi?, Eve Ali geldi., Ali'nin eve geldiği biliniyor. gibi

Caner Kerimoğlu, Genel Dilbilime Giriş (Ankara: Pegem Akademi Yayınları, 2014) 67.

Ör. bk. Gencan (2001), Korkmaz (2007), Karaağaç (2012).

Noam Chomsky, Aspects of The Theory of Syntax (Cambridge: THE M.I.T. Press, 1965) 17-18; Noam Chomsky, Syntactic Structure (The Hagua Paris: Mouton Publishers, 1957) 61-70. 
tümceleri üretmeye olanak vermektedir. ${ }^{4}$

Kuramın sonraki aşamasında derin yapı-yüzey yapı kavramlarına yoğunlaşan Chomsky, söz diziminde her birimin yüzey yapıya taşınamayacağını, bunun ancak derin yapıda saklı olduğunu dile getirmektedir. Kendinden önce gelen Yapısalcıların biçim farklıysa anlam da farklıdır görüşüne katılmayan Chomsky, aslolanın zihindeki soyut anlamsal bileşeni oluşturan derin yapının olduğu, yüzey yapının ise ikincil olduğu düşüncesine sahiptir. ${ }^{5}$ Aşağıda yer alan diyalogda yüzey yapıda yazılmayan ancak derin yapıda parantez içinde gösterilen söz dizimsel ve morfolojik unsurlar yer almaktadır:

A: Sen bugün bizim eve gelecek misin?

B: Evet, (ben bugün sizin eve geleceğim).

Chomsky, kuramının sonraki aşaması olan Yönetme ve Bağlama Kuramı'nda Evrensel Dilbilgisi yaklaşımı içinde geçen İlkeler ve Değiştirgenlerden (Principles and Parametres) bahsetmektedir. Dil denilen olgunun evrensel ilkelerinin olduğunu bununla birlikte her dilin de kendine özgü değiştirgenlere sahip olduğunu savunmaktadır. Uzun'a göre dil bilgisi, Evrensel Dil Bilgisi’nin önceki biçimlendirmelerinden farklı olarak kurallarla değil, doğuştan getirilen düzeneğin bileşenleri olarak bir dizi ilke ve değiştirgenlerle kurulmaktadır. İlkeler ve Değişstirgenler Kuramı'na göre dil bilgisi bileşenlerden değil, her birinde ilkelerin ve değiştirgenlerin etkili olduğu sunuluşlardan oluşmaktadır. Böylece her ikisinin de yapı olduğu varsayılan sesbilimsel, anlambilimsel ve bu ikisinin arasındaki bağlantının kurulduğu söz dizimsel sunuluştan oluşan bir görünüm taşımaktadır. ${ }^{6}$ Böylece diller sahip oldukları olanaklar doğrultusunda dönüşüm ve değişim kurallarına tabi olmaktadır. Chomsky, her öbekte bir yöneticinin olması durumu için ilke (principle), öbeklerdeki yöneticilerin başta veya sonda olması durumu içinse değiştirgen (parameter) kavramını kullanmaktadır. İlkeler tüm dünya dillerinde ortak olan çerçeveyi belirler, değiştirgen bu ilkenin uygulaması aşamasıyla ilgilidir ve dünya dillerindeki kullanım çeşitliliğini belirler. ${ }^{7}$

Yönetim ve Bağlama Kuramı (Government and Binding Theory) içinde yer alan İlkeler ve Değiştirgenler Kuramı, farklı türden alt kuramları içermektedir. Stnırlama, Rol, Bağlama, Yönetme, Durum ve Denetleme olmak üzere siralanabilecek olan alt alanlar arasında Uzun, Taşıma'yı da saymaktadır. Ona göre Taşıma Kuramı (Movement Theory), derin yapının yüzey yapıya döşenmesini sağlayarak derin yapıya uygulanan bir işlemdir. Yüzey yapıların sonraki düzlemlere girdi olmasına bakılarak taşımaların yüzey yapılara uygulandığı varsayılır ve

4 Ayrica bk. İmer vd. (2011: 102), Vardar (2002: 82).

5 Kerimoğlu, Genel Dilbilime Giriş, 72.

6 Nadir Engin Uzun, Anaçizgileriyle Evrensel Dilbilgisi ve Türkçe (İstanbul: Multilingual Yayınları, 2000) 91.

7 Annette Becker ve Markus Bieswanger, Introduction to English Linguistics (UTB Basics, 2006.) 101; Kerimoğlu,

Genel Dilbilime Giriş, 80-81. 
dönüşümlere uygulanışı taşıma ile belirlenir. ${ }^{8}$ Dönüşümü, bir tümcenin derin yapıdan yüzey yapıya geçmesini sağlayan kural/kuralların uygulanmasıyla ortaya çıkan süreç olarak tanımlayan Bayraktar, dönüşümün dizimsel kuralların ürettiği soyut yapıları yeni yapılara ve tümcelere dönüştürdüğünü belirtmektedir. ${ }^{9}$ Yaylagül'e göre dönüşümler yüzey yapıdaki söz dizimlerini etkiler fakat aslında derin yapı düzeyinde yer alır. Derin yapı soyut biçimlerden, sözcük ve yapı türlerinden oluşur. Bu biçimleri temsil eden simgeler, dönüşüm talimatlarında kullanılır. Son dönüşüme kadar tümceler, bu terimlerle kurulur ve sözcükler sürecin sonunda işe dahil olur. Derin yapılar inşa etmek için tekrar yazım kurallarına ihtiyaç vardır ve birimler aynı cins başka birimler içine dâhil edilebilir. Yani bir eylem öbeği içinde yer alan bir ad öbeği daha sonra başka bir ad öbeği içine yerleştirilebilir. ${ }^{10}$

Dönüşümün gerçekleşmesini sağlayan işlemlerden biri olan taşıma işlemi, Kadri Kuram’a göre söz dizimsel sunuluşta yer alan bir kurucuya uygulanan ve kurucunun bir sonraki sunuluşta başka ama boş olan bir konuma taşınmasıdır. Taşıma sonucunda taşınan sözcük arkasında bir $i z$ (trace) bırakır ve yeni konumundayken de eski konumuyla ilişki kurar. Taşımanın ilkeleri arasında taşınan ögenin sadece kendi kategorisinden bir ögenin bulunabileceği konuma taşınması yer almaktadır. Örneğin öbeğin öbek konumuna asıl unsurun da asıl unsur konumuna taşınması gerekmektedir. ${ }^{11}$ Diğer bir deyişle taşıma, söz dizimsel sunuluşta yer alan bir kurucuya uygulanan ve bu kurucunun bir sonraki sunuluşta başka ama boş olan bir konuma hareket etmesini içermektedir. ${ }^{12}$ Haegeman, boş kategorinin tematik özellikleri dikkate alındığında sıfir unsur 'un (zero element) türünün adıllar ve izler olduğunu söylemektedir. Derin yapısının boşluğundaki tematik rollere sahip unsurlar, yalnızca adıl olabilmekte ve izleri de yüzey yapı olgusu içinde değerlendirilebilmektedir. Yüzey yapısında bir öncülü olan bir boş unsur (null element), adıl veya iz olabilir. Öncül ve açık olmayan unsurların her birinin rolü varsa boş unsur bir iz olarak tanımlanacaktır. ${ }^{13}$ Taşıma sürecinde taşınan kurucunun eski konumu ile konma noktası denilen yeni konumu arasında yapısal bir ilişki vardır. Taşınan kurucu arkasında bir iz bırakmakta ve bu iz ile kurucu eş dizinlenmektedir. ${ }^{14}$

Taşıma işleminde taşınan unsurun türü ve konma noktasına göre taşıma türlerinin de farklılaştığı söylenebilir. Chomsky'nin İngilizce üzerinden yaptığ 1 tespitler neticesinde temel olarak üç taşıma kategorisinden bahsedilmektedir: Ad öbeği taşıma (AÖ-taşıma "NPmovement”), baş unsur taşıma (head-movement) ve ne taşıma (wh-movement). Ad öbeği taşıma, Türkçede de örnekleri görülen bir dönüşüm, dolayısıyla taşıma türüdür. Bu taşıma türünün en

8 Uzun, Anaçizgileriyle Evrensel Dilbilgisi ve Türkçe, 95.

9 Nesrin Bayraktar, Dil Bilimi (Ankara: Nobel Yayınları, 2014) 117.

10 Özen Yaylagül, Göstergebilim ve Dilbilim (Ankara: Hece Yayınları, 2015) 110.

11 Kadri Kuram, Türkçede Yer Öbeklerinin Bazı Sözdizimsel Özellikleri (Ankara Üniversitesi, Yayımlanmamış Yüksek Lisans Tezi, 2006.) 5-6.

12 Uzun, Anaçizgileriyle Evrensel Dilbilgisi ve Türkçe, 290.

13 Liliane Haegeman Introduction to Government and Binding Theory (UK/USA: Blackwell Publishers, 1994) 434.

14 Murat Özgen, Formalist Dilbilgisi Kuramları (Ankara: Pegem Akademi Yayınları, 2018) 25. 
belirgin örneklerinden birinin edilgenleştirme olduğunu söyleyen Özgen, taşınan birimin de bir ad öbeği olması sebebiyle bu işlemin bir AÖ-taşımasını teşkil ettiğini dile getirmektedir. ${ }^{15}$ Baş unsur taşımada taşınan öge yalnızca öbeğin başı yani yönetici konumundaki sözcüktür. Başla beraber taşınan öbek yapı da yeni konumunda aynen korunmakta ve bölünmemektedir. Örnekleri en çok Avrupa dillerinde uygun görülen ne taşıma ise tümcenin başında bulunan soru sözcüğü ya da örneğin İngilizcedeki will, have gibi yardımcı eylemlerin tümcenin başına getirilmesidir. Tümcenin soru anlamı ancak bu şekilde verilebilir. Dolayısıyla bu taşıma bahsi geçen diller için zorunlu görünmektedir. Söz konusu taşıma türleri ve Türkçede görülen karşılıkları aşağıda ayrıntılı olarak ele alınacaktır.

\title{
1.1. Ad Öbeği Taşıma
}

Ad öbeği taşıma, tam anlamıyla yüzey yapının bir üyesinin başka bir yüzey yapıda görünmesidir. Ancak önemli olan koşul, derin yapıdaki karşılığının önceki yüzey yapıdaki sunuluş ile aynı görevde yani rolde olmasıdır. Uzun, bu tip taşımalarda kurucuların ne kadar uzağa taşındıklarına yani öbek sınırlarının sayısına göre de göreceli olarak taşımanın farklılaştığını söylemektedir. ${ }^{16}$ Yapılan çalışmalarda en belirgin ad öbeği taşımasının geleneksel dil bilgisinde etken-edilgen türü olarak geçen tümce dönüşümlerinde görüldüğünü söylemektedir. Tümcede etkilenen veya harekete konu olan unsur, edilgen yapıda yüklemcil ögeye yaklaşmaktadır. Aşağıda yer alan 2 numaralı a ve b örneklerinde tümceyi oluşturan unsurların üstlendikleri roller, taşımanın etkisiyle değişikliğe uğramıştır. 2a tümcesinde harekete konu olan nesne rolünde olan unsur, 2b tümcesinde, her tümcenin özne bulundurması zorunluluğu ilkesi gereği, tümcenin boş olan konumundaki özne konumuna taşınmıştır. Derin yapısı eş anlamlı olan tümceler, taşımanın etkisiyle yüzey yapıda farklı görünmektedir.

(2)

\author{
a. Ayse bulașlklart yıkadl. \\ Eyleyen konu yüklemcil öge \\ b. Bulassılar yılkandl. \\ Eyleyen yüklemcil öge
}

15 Özgen, Formalist Dilbilgisi Kuramlart, 25.

16 Uzun, Anaçizgileriyle Evrensel Dilbilgisi ve Türkçe, 290. 


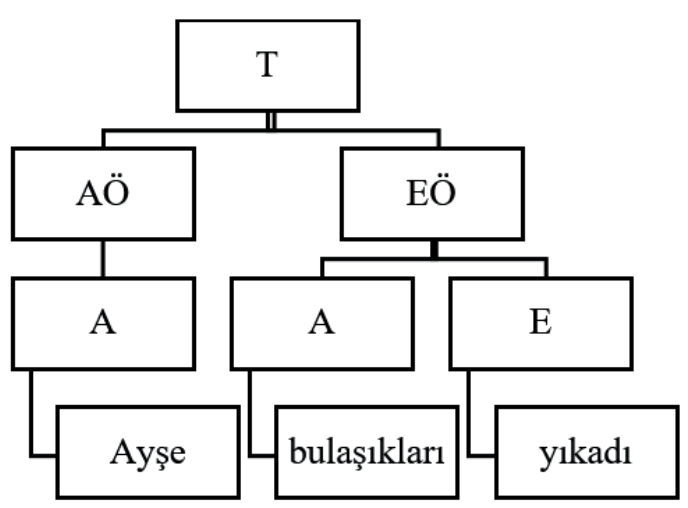

Şema 1: 2a'nın gösterimi

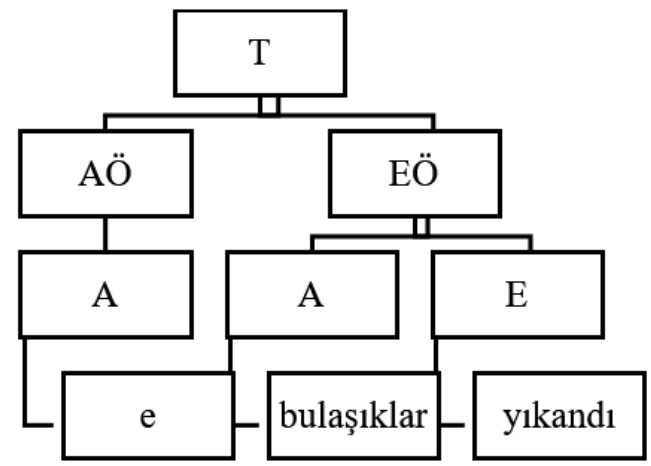

Şema 2: 2b'nin gösterimi (taşımadan önce)

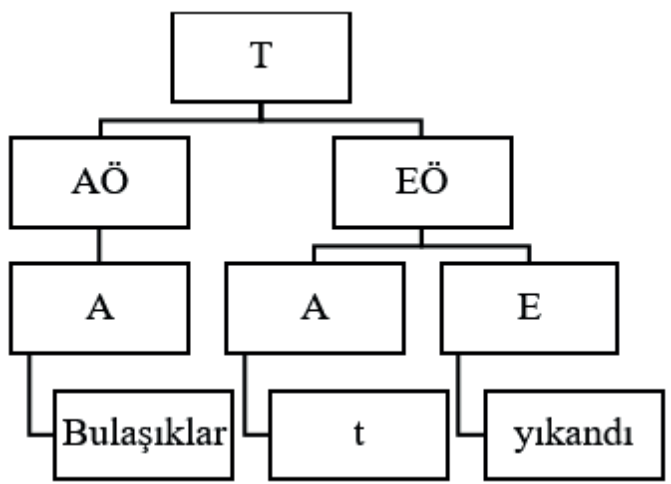

Şema 3: 2b’nin gösterimi (taşımadan sonra) 
Kaynaklarda ad öbeği taşımanın en tipik örneği olarak edilgenleştirme gösterilse de tümce yapısının ettirgen hale gelmesi de ad öbeği taşımasının ileri seviyesi kabul edilebilir. 3 numaralı tümcede b, a'nın ettirgen biçimi olarak görüldüğünde temizlikçiler sözcüğü, ilk tümcenin ikincil eyleyeni ${ }^{17}$ konumunda yer alırken b tümcesinde eyleme konu olan rolünde görünmektedir. Temizlikçiler varsayımsal ad öbeği, temizleme hareketinin birincil eyleyeni olmasına rağmen yüzey yapıda ilk tümceden arta kalan boşluğu doldurmaktadır. Bu tip ettirgen dönüşümlerde çekirdek tümce yapısında olan ilk tümcede silme işlemi uygulandığı gibi taşınan unsurlar ettirgen tümcede ana yüklemcil ögenin konusu olarak görev yapmaktadır.

(3)

a. Ayşe temizlikçilere evi temizlemeleri için emir verdi.

b. Ayşe evi (temizlikçilere) temizletti.

Chomsky’nin kuramında yer vermediği ancak pek çok dilde örneği görülebilecek olan eylem tümcelerinin ad tümcesi formuna dönüşümlerinde taşıma kuralları devreye girmektedir. Taşınan unsur, eylem tümcesinde başka bir konumda yer alırken ad tümcesinde daha farklı bir konumda görülebilir. Aslında eylem tümcelerinin ad tümcesine dönüşme işleminde birden farklı form elde edilebilir. Elde edilen her formla beraber unsur, bir önceki konumdan diğer sunuluştaki başka bir konum ve role gelmektedir. Aşağıda 4 numaralı örneklerde b ve c tümceleri a tümcesinin dönüşüme uğrayarak ve form değiştirerek elde edilmiş hâlidir. Hepsindeki ortaklık derin yapılarının aynı olmasıdır. Dolayısıyla b ve c'den başka tümce de üretilebilir. İlk tümcede senin yürüyüşün şeklinde olan ad öbeği, tümcenin harekete konu olan nesnesi durumundadır. A tümcesinde nesne olan ad öbeği adıl düşürerek ve başka bir öbeğin üyesi gibi görünerek tümcenin öznesi konumuna gelmektedir. Eylem tümcelerinin ad tümcesine dönüştürülmesinde eksiltmeler, yer değiştirmeler ve eklemelerle taşıma işlemi tamamlanmaktadır. Aslında b tümcesi ile a tümcesi çözümleme olarak birbirine paraleldir. Yüzey yapıda özne olarak görünen üye, aslında tümcenin derin yapısında yine nesne konumunda yer almaktadır ancak bu sefer başka bir öbeğin bileşeni olarak. Aynı durum c tümcesi için de geçerlidir. İlk tümcenin nesne konumunda olan unsuru, bu kez yüklemcil ögede ve üstelik b'den farklı olarak aynen yani eksiltme ve ekleme olmadan konumlanmaktadır.

(4)
a. Senin yürüyüșünü beğeniyorum. Nesne yüklemcil öge
b. Beğendiğim bir yürüyüșün var. Özne yüklemcil öge
c. $\frac{\text { Beğendiğim șey }}{\text { Özne }} \frac{\text { senin yürüyüș̈̈n. }}{\text { yüklemcil öge }}$

$17 \mathrm{Bu}$ örnek için emir veren yani birincil eyleyen rolünde olan unsur $A y s ̧ e$ ' dir. İç tümcenin yani temizleme eyleminin eyleyenleri konumunda olan unsur olarak temizlikçiler, ikincil eyleyen olarak yer almaktadır. 
Türkçede diğer bir ad öbeği taşıma örneği, ne ...ne (de) bağlacı ile kurulan tümcelerde görülmektedir. Bu tip tümcelerde yüklemcil ögede yer alan olumlu görünümlü unsur derin yapıda olumsuzluk bildirmektedir. Dolayısıyla olumsuz yeniden yazmada boş kategori doldurulmamakta ancak taşıma işlemi sırasında eksilme meydana gelmektedir. 5a'da yer alan tümcenin yeniden yazımı b'de verilmektedir. 1a'da yüzey yapıda iki ayrı tümce görünümünde olan yapı, derin yapıda tek eylem ve tek eyleyeni barındırmaktadır. Bununla birlikte yüklemcil öge tekleşerek biri silinmekte ve yüklemcil öge ve eyleyen uyumunun sonucunda morfolojik şahıs belirtici değişime uğrayarak çokluk bildirmektedir.

(5)

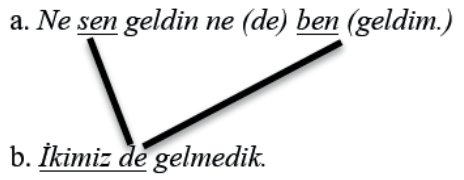

\subsection{Baş Unsur Taşıma}

Taşınan unsurun, öbeğin baş unsuru olduğu taşıma türüne baş taşıma ya da baş unsur taşıma denmektedir. Uzun, ad öbeği taşımasındaki gibi büyükçül bir yansımanın olmadığını, taşınan ögenin yalnızca baş unsur olduğunu dile getirmektedir. İngilizcede özne-yardımcı eylem (YAR) değiştirimi dönüşümü olarak bilinen işlem, baş taşımanın gözlendiği tipik işlemdir. Evet/hayır soruları, özne ile yardımcı eylemin yer değiştirmesini gerektirmektedir. ${ }^{18}$

(6)

a. You are a student. (Sen öğrencisin.)

b. Are you a student? (Sen öğrenci misin?)

Yukarıda bahsi geçen taşıma tipi Türkçe gibi yer değiştirme işlemi ile soru formunun elde edilmediği diller için geçerli değildir. Türkçede baş taşıma ancak yine öbek yapılar içinde kendini göstermektedir. Bu yer değiştirme işleminden başka Özgen'e göre bu işlemde bir baş başka bir başa eklemlenmektedir. Buna göre eylemin zaman, görünüş, kip, olumsuzluk, çatı gibi biçimbilimsel olarak eklemlenebilmesi için zaman öbeğinin $\left(Z^{0}\right)$ başına kadar çıktığı varsayılır. Ana eylemden zaman öbeğine yapılan bu taşıma ile eylem başın kendisine eklemlenir. ${ }^{19}$ Türkçede zaman öbekleri yalnızca zaman bildiren sözcüklerle kurulduğu için zaman eki taşıyan yapılar zaman öbeği adı altında değerlendirilmemektedir. Ancak zaman eki almış bir eylemle birleşen eylem, zaman öbeği olarak düşünülen öbeğin başına taşınarak dönüşüme uğrayabilir. Aşağıda yer alan 7 numaralı tümce zaman öbeğinin eylemin başına taşınmasını göstermektedir:

18 Uzun, Anaçizgileriyle Evrensel Dilbilgisi ve Türkçe, 292-293.

19 Özgen, Formalist Dilbilgisi Kuramları, 26. 
(7)

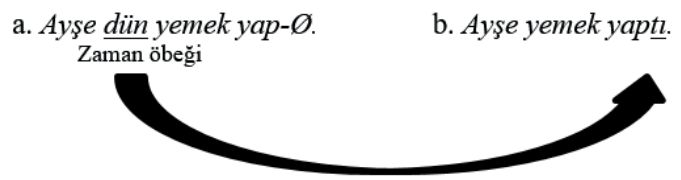

\subsection{Ne Öbeği Taşıma}

Soru sözcüklerinin tümcenin başına taşınması işlemi olarak adlandırılan ne öbeği taşımanın amacı bu öbeklerin tümcede soru açısı alabilmeleridir. Özgen'e göre bunlar ancak tümce başına getirilerek diğer bir deyişle tümleyici öbeğinin göstericisi konumunda bulundurularak açık taşıma örneği sergilemektedir. ${ }^{20}$ İmer vd., İngilizceden örnek vererek "What did you buy?" (Ne satın aldın?) tümcesinde what sözcüğünün derin yapıda buy sözcüğünün nesnesi olduğunu söylemektedir. ${ }^{21}$ Türkçede ise durum İngilizcede görülenden biraz daha farklıdır. Türkçede soru sözcüklerinde görülen taşıma işlemi zorunlu değildir. Bu açıdan mantıksal yapı içinde ele alınabilecek düzeyde odaklanmayı gerektirmektedir. Soru sözcügünün konumlandığı yer zorunlu değil bilinçli ve anlambilimsel bir tercihle gerçekleşen taşımayı içermektedir. Aşağıda yer alan 8 numaralı örnekler a tümcesinden taşıma ile gerçekleşen soru formlarını göstermektedir.
(8)
a. Ben bugün size geleceğim .
b. Bugün bize kim gelecek?
c. Kim bugün bize gelecek?
d. Bugün kim bize gelecek?

Yukarıda verilen örnekler, dönüşüm türlerinden çalkalama denilen işleme de girmektedir. Söz konusu yer değiştirmelerin yapılabilmesi söz diziminde unsurların izin verdiği serbestlik ölçüsünde gerçekleşmektedir. Ancak soru sözcüklerinde yapılan taşıma, yüklemcil ögeye göre konumlandığı ve mantıksal yapı içinde yer aldığ 1 için çalkalamadan farklılık göstermektedir.

Chomsky’nin kuramında bahsettiği üç taşıma işleminin yanı sıra Türkçeye uygulanabilecek olan ve Türkçede var olan söz dizimsel yapıyla ilgili farklı taşımalardan da söz etmek gerekmektedir.

\subsection{Tümce Taşıma}

Türkçe üzerine yazılmış çeşitli kaynaklarda aslında Farsça tümce diziminden Türkçeye geçmiş olan ki bağlaçlı tümce yapısı, taşıma işleminin en kolay uygulanabileceği alandır. İki ayrı tümcenin $k i$ ile bağlandığı ve $k i$ 'li birleşik tümce gibi adlandırmaların kullanıldığ

20 Özgen, Formalist Dilbilgisi Kuramlarl, 26-27.

21 Kamile İmer, Ahmet Kocaman ve Sumru Özsoy, Dilbilim Sözlüğ̈̈ (İstanbul: Boğaziçi Üniversitesi Yayınevi, 2011) 192. 
bu tümce tipinde tümce iki ayrı yapı gibi düşünülebileceği gibi iç tümceli tek bir yapı haline de getirilebilir. $K i$ bağlaçlı tümcelerde taşıma için iki işlemin uygulanması mümkündür. Aşağıda yer alan 9a tümcesinin iki formda yazılabildiği görülmektedir. 9b tümcesinin yüzey yapı çözümlemesi 9a ve 9c'nin çözümlemesinden büyük farklarla ayrılmaktadır. Ancak derin yapıda üç tümce de birbiriyle aynı görünüme sahiptir. Buna göre 9a ve 9c'de yüklemcil öge görevinde olan konuş- eyleminin 9b'de iç tümcede yüklemcil öge görevi üstlendiği ve bununla beraber $d u y$ - eyleminin de duyulan nesnesine karşılık gelecek biçimde taşındığı görülmektedir.
(9)
a. Duydum ki hakkımda çok konuşuyormuşsun.
b. Hakkımda çok konuştuğunu duydum.
c. Hakkımda çok konuşuyormuşsun. Duydum.

Ki bağlaçlı tümcelerin çözümlenmesi için taşıma işlemine ihtiyaç vardır. Aksi takdirde $d u y$ ve konuş- birer yüklemcil öge olarak değerlendirileceği için $d u y$-eyleminden önce pek çok boş kategori ortaya çıkmaktadır. Kalan izler, yalnızca ki' den sonraki unsurlarla cevaplanabileceği için 9b örneğindeki gibi bir taşımayla boş kategoriler doldurulabilecektir.

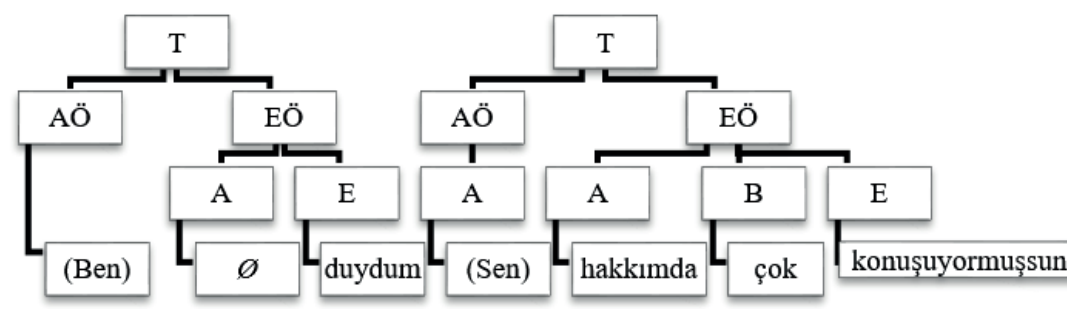

Şema 4: 9a’nın gösterimi

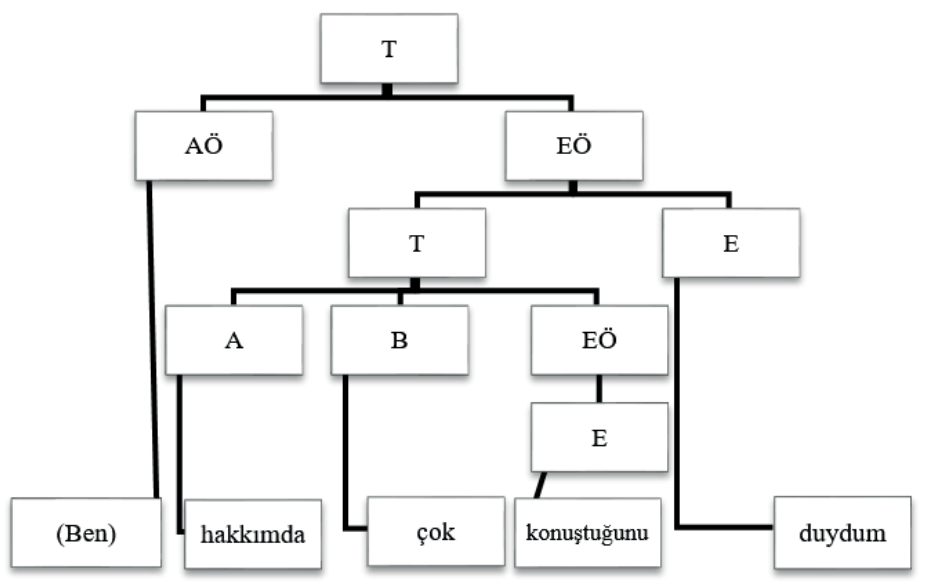

Tablo 2: 9b'nin gösterimi (Taşımadan sonra) 
$K i$ bağlaçlı tümcelerdekine benzer durum çünkü bağlacıyla birbirine bağlanan tümceler için de geçerlidir. Yüzey yapıda iki ayrı tümce diziliminde yer alan tümceler derin yapıda da tek olarak görünmekte ve yüklemcil ögedeki hareketin sebebi veya amacı rolüyle görev yapmaktadır. Dolayısıyla aşağıda yer alan 10b tümcesinde ilk tümcede görünen herkes nesnesi/eyleme konu olan varlığ 1 ve söz ver- eylemi ikinci tümcede boş konumda olan amaç rolünde görülmektedir. $\mathrm{Bu}$ taşıma işlemi sonucunda ise yüzey yapıda yüklemcil ögede tekleşme meydana gelmektedir.

a. Ders çalışmalısin çünkü herkese söz verdin.

b. Herkese söz verdiğin için ders çalışmalısın.

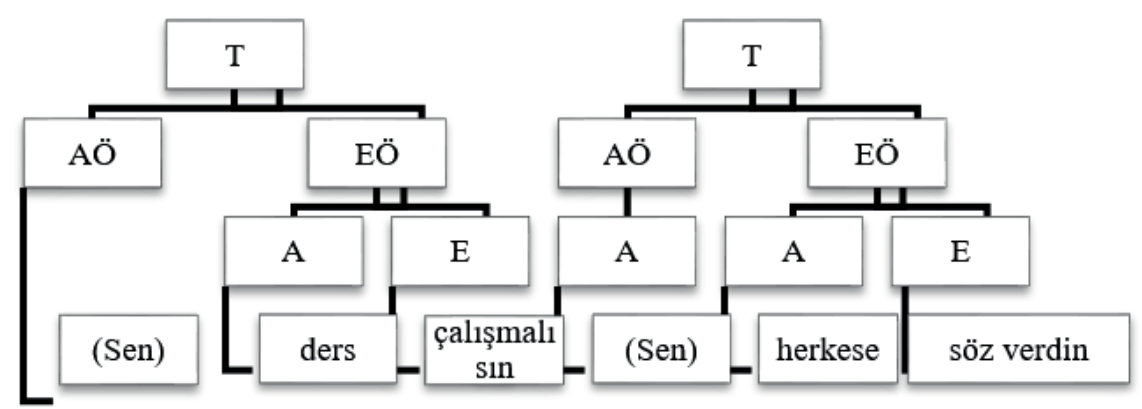

Tablo 3: 10a'nın gösterimi

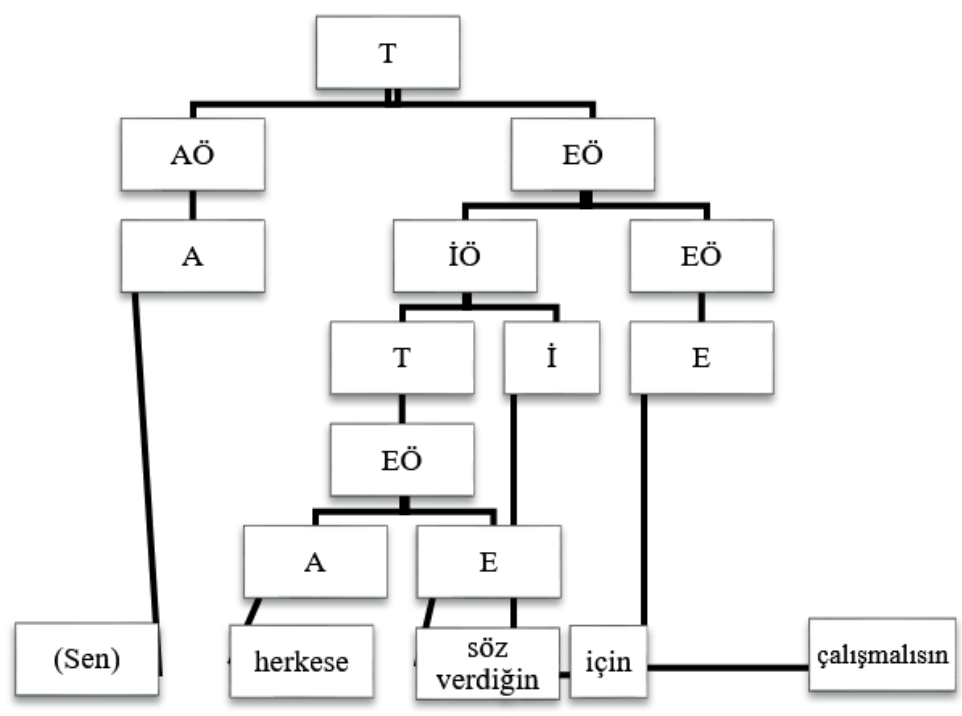

Tablo 4: 10b'nin gösterimi (Taşımadan sonra) 


\section{Sonuç}

Chomsky'nin 1980 sonrasında geliştirdiği ve Evrensel Dil Bilgisi Kuramı'nın içinde yer alan İlkeler ve Değiştirgenler Kuramı, dillerin ortak ve farklı yasalarına yaklaşımı içermektedir. Kuramın içinde yer alan alt kuramlar dillerde ortak olan değişim ve dönüşüm kurallarını ortaya koymaktadır. Söz dizimin ve öbek yapı kurallarının gerektirdiği ölçüde dönüşüme uğrayan yapılar sayesinde yüzey yapıda olmadan da söz dizimsel unsurların yeterli olabileceği tezini savunan yaklaşım, birden farklı dönüşüm türlerini ele almaktadır. Buna göre yer değiştirme, soru veya olumsuz forma sokma, taşıma gibi dönüşüm türleri bulunmaktadır.

Bu çalışmada ele alınan dönüşüm türlerinden biri olan taşıma, Chomsky'nin özellikle İngilizce, Fransızca gibi Avrupa dilleri üzerinden yaptı̆̆ 1 tespitleri içermektedir. Araştırmacı, böylece üç taşıma işleminin uygulandığı yapı içinde ad öbeği taşıma, baş unsur taşıma ve ne taşıma türlerinden bahsetmektedir. Söz konusu türler arasında ad öbeği taşıma Türkçede yaygın olarak görülmesine rağmen diğer iki taşıma türü Türkçe için tipik değildir. Ancak bununla birlikte ad öbeği taşıma örneği olarak bilinen edilgenleştirme işlemi Türkçede ettirgen tümceler için de geçerli görünmektedir. Ad öbeği taşıma içinde sayılabilecek olan ettirgenleştirme, eylemsili tümce taşıma ve ne ...ne (de) öbeği taşımada yüzey yapıda boş kategori olarak görünen unsurlar derin yapıda bu kategorileri doldurmaktadır. Bununla birlikte Türkçede $k i$ ve çünkü bağlacıyla bağlanan tümcelerin derin yapı çözümlemesinde daha açık biçimde görünen taşıma işlemi yalnızca boş kategorileri doldurmakla kalmayıp aynı zamanda başka boşluklara da yeni görevler atamaktadır.

Tüm dünya dillerine özgü olan dönüşüm ve dolayısıyla taşıma işlemi dillerin doğası gereği söz dizimsel değiştirgenler çerçevesinde ilkeler meydana getirmektedir. Böylece bir tümcenin birden fazla ve farklı yolla üretimi mümkün olabilmektedir.

\section{Kaynaklar}

Bayraktar, Nesrin. Dil Bilimi. Ankara: Nobel Yayınları, 2014.

Becker, Annette; Bieswanger, Markus, Introduction to English Linguistics, UTB Basics, 2006.

Chomsky, Noam. Aspects of The Theory of Syntax. Cambridge: THE M.I.T. Press, 1965.

Chomsky, Noam. Syntactic Structure. The Hagua Paris: Mouton Publishers, 1957.

Gencan, Tahir Nejat. Dilbilgisi. Ankara: Ayraç Yayınları, 2001.

Haegeman, Liliane. Introduction to Government and Binding Theory. UK/USA: Blackwell Publishers, 1994. İmer, Kamile, Ahmet Kocaman ve Sumru Özsoy. Dilbilim Sözlüğü. İstanbul: Boğaziçi Üniversitesi Yayınevi, 2011. Karaağaç, Günay. Türkçenin Dil Bilgisi. Ankara: Akçağ Yayınları, 2012.

Kerimoğlu, Caner. Genel Dilbilime Giriş. Ankara: Pegem Akademi Yayınları, 2014.

Korkmaz, Zeynep. Türkiye Türkçesi Grameri. Ankara: TDK Yayınları, 2007.

Kuram, Kadri. Türkçede Yer Öbeklerinin Bazı Sözdizimsel Özellikleri. Ankara Üniversitesi, Yayımlanmamış Yüksek Lisans Tezi, 2006.

Özgen, Murat. Formalist Dilbilgisi Kuramları. Ankara: Pegem Akademi Yayınları, 2018. 
Uzun, Nadir Engin. Anaçizgileriyle Evrensel Dilbilgisi ve Türkçe. İstanbul: Multilingual Yayınları, 2000. Vardar, Berke. Açılamalı Dilbilim Terimleri Sözlüğü. İstanbul: Multilingual Yayınları, 2002.

Yaylagül, Özen. Göstergebilim ve Dilbilim. Ankara: Hece Yayınları, 2015. 
